\title{
La pluralidad religiosa del mundo en el siglo XV a través de la carta náutica de Mecia de Viladestes (1413)*
}

\author{
Sandra SÁENZ-LóPEZ PÉREZ \\ CCHS - CSIC \\ sans_lp@cchs.csic.es
}

\begin{abstract}
RESUMEN
Este artículo se centra en la carta náutica de 1413 del mallorquín Mecia de Viladestes para descubrir, a través del análisis de sus textos e imágenes, las distintas religiones que coexistían en el mundo en el siglo XV, y cómo eran entendidas en Occidente. En este mapa, en el que hay cabida para el cristianismo, el islam y las religiones indias, parecen desvelarse también las vivencias personales de este cartógrafo, un judío convertido al cristianismo en 1391. Entre los motivos iconográficos que serán analizados se encuentran el Mar Rojo atravesado por el pueblo de Israel y el Monte Sinaí, donde Moisés recibió las Tablas de la Ley; la ciudad de Jerusalén y el Santo Sepulcro; el hâŷy o la peregrinación musulmana a La Meca; y la adoración del "ídolo de metal con nueve cabezas y nueve manos".
\end{abstract}

Palabras clave: Mecia de Viladestes, carta náutica, cristianismo, islam, judaísmo, religión india, mappamundi, peregrinación, La Meca, ídolo.

\section{ABSTRACT}

This article focuses on the nautical chart of 1413 by the Majorcan Mecia de Viladestes in order to show, through the analysis of its texts and images, the different religions which coexisted in the world of the fifteenth century, and how they were understood in the West. On this map there is space allocated for Christianity, Islam and the Indian religions; the personal experiences of the cartographer, a Jewish convert to Christianity in 1391, seem also to be revealed. Among the iconographic motifs that will be analyzed are the Red Sea which was crossed by the people of Israel and Mountain Sinai, where Moses received the Tablets of the Covenant; the city of Jerusalem and the Holy Sepulcher; the hajj or Muslim pilgrimage to Mecca; and the worshipping of the "idol of metal with nine heads and nine hands".

Keywords: Mecia de Viladestes, nautical chart, Christianity, Islam, Judaism, Indian religion, mappamundi, pilgrimage, Mecca, idol.

Fueron las circunstancias históricas y geográficas las que determinaron que a finales de la Edad Media, la isla de Mallorca se convirtiera en uno de los principales focos cartográficos. Tras su Reconquista por Jaime I en 1229-1231, Mallorca pasó a formar parte de la Corona de Aragón, y dentro de ella, desempeñó un papel fundamental en su economía eminentemente comercial, gracias a que, debido a la privilegiada posición geográfica de la isla - prácticamente equidistante de las costas catalanas, valencianas, andalusíes, norteafricanas, sardas y occitanas-, era la prin-

* Quiero agradecer a Matilde Miquel Juan, Dorothee Heim y Mónica Herrera Casais la ayuda prestada en la realización de este artículo. 
cipal encrucijada de las rutas marítimas mediterráneas. Este comercio favoreció un potente desarrollo en todos los aspectos de la industria naval, entre ellos, el de la realización de instrumentos para la navegación, tales como brújulas y cartas náuticas, cuya producción fue canalizada esencialmente en la isla de Mallorca ${ }^{1}$.

La mayoría de las cartas náuticas que han llegado a la actualidad no fueron utilizadas a bordo de embarcaciones, sino concebidas como obras de colección, y decoradas con lujosos materiales y numerosas imágenes. Según la descripción de mappamundi dada por Cresques Abraham en su célebre Atlas Catalán (1375)², el propósito de estos suntuosos mapas era el de representar la ymage del mon e de les diverses etats del mon e de les regions que son sus la terra de diverses maneras de gens qui en ela habiten ${ }^{3}$. Así pues, la idea de "imagen del mundo" no hacía referencia exclusiva a su acepción física, es decir, a la tierra; lo que estos mapas representaban era el mundo desde una perspectiva enciclopédica que atendía a cuestiones geográficas, políticas, económicas, sociales, culturales y religiosas. Es en este último aspecto -la representación de las distintas religiones del mundo- en el que nos centraremos a continuación. Para ello, recurriremos a la producción cartográfica de Mecia de Viladestes (n. 1370; f. 1413-1423), un cartógrafo mallorquín de origen judío convertido al cristianismo, y de ella, estudiaremos concretamente su carta de $1413^{4}$, uno de los mapas más importantes de la Edad Media por su riqueza artística. Asimismo, para profundizar en el conocimiento que se tenía de la pluralidad religiosa a finales de la Edad Media, y cómo las distintas religiones eran entendidas en Occidente, cotejaremos los motivos de su carta con aquellos que aparecen en otras anteriores y posteriores.

1 Para la cartografía náutica mallorquina, véase J. REY PASTOR y E. GARCÍA CAMARERO, $L a$ cartografía mallorquina, Madrid, 1960; T. CAMPBELL, "Portolan Charts from the Late Thirteenth Century to 1500", J.B. HARLEY y D. WOODWARD (eds.), Cartography in Prehistoric, Ancient, and Medieval Europe and the Mediterranean. The History of Cartography, vol. 1, Chicago, 1987, pp. 371-463; Cartografía Mallorquina, Barcelona, 1995; V.M. ROSSELLÓ I VERGER, "Les cartes portolanes mallorquines", Cicle de conferències sobre història de la cartografia $\left(10^{\circ}\right.$ 1999, Barcelona). La cartografia catalana, Barcelona, 2000, pp. 19-115; S. SÁENZ-LÓPEZ PÉREZ, Imagen y conocimiento del mundo en la Edad Media a través de la cartografía hispana, Tesis Doctoral, Universidad Complutense de Madrid, Madrid, 2007, pp. 291-713; y R.J. PUJADES I BATALLER, Les cartes portolanes. La representació medieval d'una mar solcada, Barcelona, 2007.

2 Bibliothèque nationale de France (en adelante BnF), París (Ms. espagnol 30). Para una reproducción facsimilar de este mapa, véase CRESQUES ABRAHAM, Mapamundi del año 1375 de Cresques Abraham y Jafuda Cresques, Barcelona, 1983; y El món i els dies. L’Atles Català, Barcelona, 2005.

3 "Imagen del mundo, de sus diversas épocas, de las diversas regiones que hay sobre la tierra y las diferentes razas que viven en ella", CRESQUES ABRAHAM, op. cit., 1983, p. 15.

4 BnF, París (Rés. Ge. AA 566). Para una reproducción de esta carta, véase G. MARCEL, Choix de cartes et de mappemondesdes des XIVe et XVe siècles, París, 1896; Y. KAMAL, Monumenta cartographica Africae et Aegypti, t. IV, fasc. III, El Cairo, 1926-1951, fols. 1367v-1368 y 1368v-1369; y R.J. PUJADES I BATALLER, op. cit., 2007, fig. C30, pp. 202-203. Para una aproximación a esta carta, véase J.M. GIRONÉS GUILLEM, "El Portulano de Mecià de Viladestes (1413). Un antiguo tesoro de Valldecrist, de nuevo resplandeciente", La Cartuja de Valldecrist (1405-2005). VI Centenario del inicio de la Obra Mayor, Castellón, 2008, pp. 183-208. 


\section{El cristianismo frente a otras religiones}

En sus representaciones del mundo, los cartógrafos occidentales de la Baja Edad Media se esforzaron por plasmar la geografía religiosa, y especialmente por distinguir los territorios bajo dominio cristiano de los restantes. Estos últimos estaban ocupados por pueblos de distintas etnias y creencias, entre los que se mencionan a paganos, sarracenos, tártaros e idólatras. La religión de un determinado territorio se definía gráficamente a través de la insignia correspondiente, de su soberano o de sus ciudades. En la carta de Mecia de Viladestes (1413) apreciamos distintos tipos de ciudades, dependiendo del lugar del mundo en el que se localizan. Los territorios cristianos, que abarcan Europa casi en su totalidad, y otras regiones, como la africana bajo dominio del mítico soberano cristiano Preste $\mathrm{Juan}^{5}$, muestran torres rematadas en cruz. Los continentes asiático -bajo dominio mongol-y africano -bajo control musulmán- optan por torres con remate almenado o en cúpula ${ }^{6}$ (fig. 1). Probablemente, las cruces aludirían a las espadañas o torres campanario de los templos cristianos, y las cúpulas, a los alminares de las mezquitas ${ }^{7}$.

El recurso a las ciudades para diferenciar en los mapas la geografía religiosa se retrotrae al siglo XIV. Así por ejemplo, el genovés Giovanni da Carignano distinguía la soberanía religiosa mediante el color asignado a las ciudades en su carta atribuida de la primera

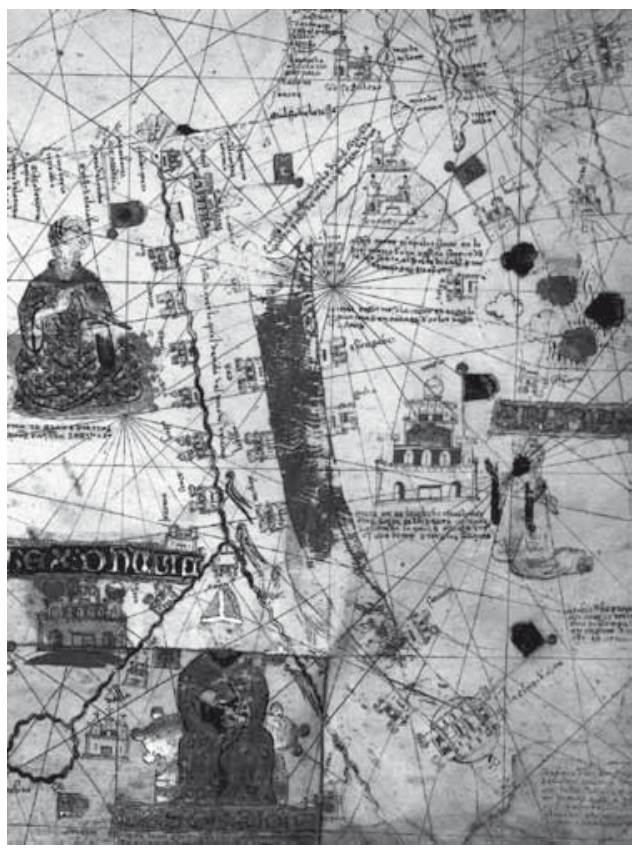

Fig. 1. Carta de Mecia de Viladestes (1413), detalle en el que se distingue el Santo Sepulcro de Jerusalén, el Monte Sinaí, el paso del Mar Rojo por el pueblo de Israel (bastante perdido), un peregrino musulmán ante La Meca, Preste Juan y ciudades cristianas rematadas en cruz, frente a las musulmanas, en almenas o cúpula (BnF, París, Rés. Ge. AA 566).

5 Para este soberano, véase C.E. NOWELL, “The historical Prester John”, Speculum, 28:3 (1953), pp. 435-455; y J. MARTÍN LALANDA (ed.), La carta del Preste Juan, Madrid, 2004.

6 Y.K. FALL, L'Afrique à la naissance de la cartographie moderne $\left(14^{\text {eme }} / 15^{\text {eme }}\right.$ siècles: les cartes majorquines), París, 1982, p. 206; y F. DE DAINVILLE, Le Langage des Géographes. Termes, signes, couleurs des cartes anciennes, 1500-1800, París, 1964, pp. 308-309.

${ }^{7}$ Las torres cupuladas de La Meca del Atlas Catalán han sido interpretadas como alminares en BIBLIOTHÈQUE NATIONALE DE FRANCE, Mapa mondí, l'Atlas Catalan, une carte du monde au XIVe siècle [CD-ROM], París, 1998; e idem, "L'architecture", <http://expositions.bnf.fr/ciel/catalan/figures/t02110.htm> (última consulta 11/01/2011). 
mitad del siglo $\mathrm{XIV}^{8}$; dos textos en el mapa, uno situado el norte de África y otro en la costa atlántica africana, explican que las ciudades pintadas de negro estaban bajo control musulmán o mongol: Nota quod omnes ciuitates que sunt tincte in aliqua parte de nigro sunt sub dominio Sarracenorum uel Tartarum ${ }^{9}$. Probablemente no es casual que el cartógrafo recurriera al negro para las ciudades no cristianas, sino que podríamos entrever en esta elección la asociación con el Mal que el cristianismo otorgaba a dicho color ${ }^{10}$. La diferencia cromática fue también empleada por el cartógrafo alemán Andreas Walsperger en su mappamundi de $1448^{11}$, donde un texto bajo el mapa explica el significado de los colores del punteado de las ciudades: Rubra puncta sunt christianorum civitates. Nigra uero infidelium in terra marique existentium ${ }^{12}$.

La distinción religiosa a través de la concepción formal de las ciudades, como veíamos en la carta de Mecia de Viladestes, tiene su origen, dentro de la cartografía náutica, en las cartas del genovés Angelino Dalorto (1330) ${ }^{13}$ y las de Angelino Dulcert -tanto la que se le atribuye de la primera mitad del siglo $\mathrm{XIV}^{14}$ como la que firma en $1339^{15}$ - . Dichos mapas definen la soberanía religiosa de las ciudades a través del remate esférico del mástil de las banderas, en el que se inserta una cruz para las cristianas, y un creciente para las restantes. Asimismo, en algunas ciudades de estas cartas, y ya de forma sistematizada

8 Archivio di Stato, Florencia (Carte nautiche 2). Para una reproducción de esta carta, véase T. FISCHER, Raccolta di mappamondi e carte nautiche del XIII al XVI secolo, Venecia, 1881; y R.J. PUJADES I BATALLER, op. cit., 2007, pp. 328-329.

9 "Nota que todas las ciudades que están pintadas en alguna parte de negro están bajo dominio sarraceno o tártaro".

10 Para el simbolismo cristiano otorgado al color negro, véase L. RÉAU, Iconographie de l'art chrétien, t. 1, Introduction générale, París, 1955, p. 73. El mapa desapareció en 1943 y no se conserva más que en una reproducción fotográfica en blanco y negro, por lo que desgraciadamente hemos perdido la impresión que causaría la diferenciación cromática de estos territorios; solo nos queda de lo que fue su rica policromía la descripción que realizaron de ella Gustavo Uzielli y Pietro Amat di S. Filippo, quienes afirmaron que estaba pintada de verde, azul, blanco, rojo y negro, en G. UZIELLI y P. AMAT DI S. FILIPPO, "Mappamondi, carte nautiche, portolani ed altri monumenti cartografici specialmente italiani dei secoli XIII-XVII", Studi biografici e bibliografici sulla storia della geografia in Italia..., Roma, 1882 (reed. Staten Island, 2000), vol. 2, p. 49.

11 Biblioteca Apostolica Vaticana, Ciudad del Vaticano (Ms. Pal. lat. 1362 B). Para una reproducción facsimilar de este mapa, véase ANDREAS WALSPERGER, Die Weltkarte des Andreas Walsperger: diese Karte stammt von der Hand des Bruders Andreas Walsperger..., Zúrich, 1981.

12 "Las ciudades cristianas tienen un punto rojo. El negro es para las infieles que existen en tierra y mar".

13 Archivio Corsini, Florencia. Para una reproducción de este mapa, véase A. MAGNAGHI, La carta nautica costruita nel 1325 da Angelino Dalorto, Florencia, 1898; ANGELINO DALORTO, The Portolan Chart of Angellino de Dalorto, MCCCXXV, in the Collection of Prince Corsini at Florence, Londres, 1929; y R.J. PUJADES I BATALLER, op. cit., 2007, fig. C7, pp. 114-115.

14 British Library, Londres (Add. Ms. 25691). Para una reproducción de este mapa, véase ibid., fig. C9, pp. 126-127.

15 BnF, París (Rés. Ge B 696). Para una reproducción de este mapa, véase G. MARCEL, op. cit., 1896; G. CAVALLO (dir.), Cristoforo Colombo e l'apertura degli spazi: mostra storico-cartografica, Roma, 1992, vol. 1, fig. I.22, pp. 164-165; y R.J. PUJADES I BATALLER, op. cit., 2007, fig. C8, pp. 120-121. 
en las de los cartógrafos mallorquines Guillem Soler ${ }^{16}$ y Cresques Abraham, encontramos el recurso que emplearía posteriormente Mecia de Viladestes de aludir al cristianismo mediante cruces, reservando las almenas y cúpulas para las restantes religiones.

Además de indicar la geografía religiosa, los cartógrafos reflejaron en sus mapas algunos de los cambios de religión que experimentaron determinados territorios en la Edad Media. Sin embargo, estas actualizaciones no se realizaron siempre con el mismo rigor, sino que mostraban una clara preferencia por el triunfo del Cristianismo ${ }^{17}$. Esto se aprecia, por ejemplo, en la representación de la Reconquista cristiana de la península Ibérica ${ }^{18}$. En su carta de 1413, Mecia de Viladestes muestra en el ángulo sureste la ciudad de Granada rematada en cúpula, mientras que otras ciudades, tales como Valencia o Toledo, así como la basílica de Santiago de Compostela en Galicia, exhiben cruces. La ciudad islámica se distingue también porque no se levanta sobre una base recta, sino en "V", es decir, en ángulo - un detalle exclusivo de Granada, con el que quizá se trataba de evocar la forma de proa de la Alcazaba del palacio nazarí-. Asimismo, esta ciudad enarbola la bandera de color rojo, tomado del estandarte de la familia de los Banū l-Aḥmar, fundadora de esta dinastía, y en la que en otros mapas, por ejemplo en el Atlas Catalán (1375), se ha conservado una inscripción en oro que imita los caracteres cúficos árabes del lema nazarí wa-lā gālib illà Allāh, es decir, "Y no [hay] vencedor sino Dios"19.

Granada aparece como ciudad islámica en la carta de Jacobo Bertrán de $1482^{20}$, donde sobre Sierra Nevada figura un soberano típicamente musulmán -sentado "a la turca" sobre un gran cojín, con una adarga en su mano izquierda y blandiendo un alfanje en la derecha-. Sus emblemas de poder islámicos contrastan con los occidentales que exhiben en el mismo territorio peninsular los soberanos de Portugal, y de Castilla y Aragón. Siete años más tarde, en 1489, este cartógrafo realizó otra carta $^{21}$, y en ella dispuso sobre la sierra granadina el escudo de los Reyes Católicos

16 De este cartógrafo conservamos dos cartas firmadas por él, una fechada ca. 1380, BnF, París (Rés. Ge B 1131); y otra en 1385, Archivio di Stato, Florencia (Carte nautiche 3). Para una reproducción de la carta de ca. 1380, véase G. MARCEL, op. cit., 1896; para la de 1385, véase Y. KAMAL, op. cit., 1926-1951, t. IV, fasc. III, fols. 1319v-1320; y R.J. PUJADES I BATALLER, op. cit., 2007, fig. C17, pp. 158-159.

17 Véase T. CAMPBELL, op. cit., 1987, pp. 398-401.

18 Véase S. SÁENZ-LÓPEZ PÉREZ, "La Reconquista cartográfica: el Islam peninsular en la cartografía medieval hispana", Treballs de la Societat Catalana de Geografia, 61-62 (2006), pp. 279-301, esp. $295-297$.

19 Para la enseña de la dinastía nazarí, véase P.C. LUX-WURM, Les drapeaux de l'Islam de Mahomet à nos jours, París, 2001, p. 111; y V. MARTÍNEZ ENAMORADO, “'Lema de príncipes’: Sobre la gāliba y algunas evidencias epigráficas de su uso fuera del ámbito nazarí”, Al-Qanțara, $27: 2$ (2006), pp. 529-550, esp. 537-538.

${ }^{20}$ Archivio di Stato, Florencia (Carte nautiche, no. 7). Para una reproducción de este mapa, véase G. CAVALLO, op. cit., 1992, vol. 1, pp. 436-437.

21 Biblioteca Marucelliana, Florencia (Dis. B. 237). Para una reproducción de este mapa, véase ibid., fig. II.13, pp. 318-319. 
junto a la figura de un monarca, posiblemente el rey Fernando, con una granada en la mano ${ }^{22}$. Aunque la Reconquista de Granada no finalizó hasta 1492, Jacobo Bertrán recurrió a un escudo de pretensión con el que parecía tomar partido en la contienda y mostrar su respaldo hacia la victoria cristiana; muy posiblemente este cartógrafo se hacía eco del espíritu optimista que se respiraba, puesto de manifiesto en la política de los Reyes Católicos desde finales de 1489. Poco después, a principios del siguiente año, tan solo quedaban en manos islámicas la capital granadina y los territorios inmediatos, y el 18 de enero de 1490, los Reyes Católicos anunciaban prematuramente al concejo de Sevilla el fin de la guerra de Granada y los tratos con Boabdil para la entrega de esta ciudad:

“...Sabed que después de muchas fatigas e trabajos e gastos ha placido a la misericordia de Nuestro Señor dar fin a la guerra del Reyno de Granada; e por quel rey Muley Babdili, que al presente tiene la çibdad de Granada, tiene asentado e conçertado de entr egar a nos e a nuestras gentes la dicha çibdad de Granada, al qual nos auemos enbiado nuestros mensajeros para asentar con él el tienpo en que nos aya de entregar la dicha çibdad, y la respuesta e asiento desto non se podrá dilatar a lo más por veynte dias primeros..." 23 .

La importancia del Cristianismo se pone también de relieve en las cartas náuticas a través de la representación de algunos de sus principales santuarios, como las basílicas de Santiago de Compostela en Galicia y San Pedro del Vaticano en Roma, el monasterio de Santa Catalina en el Monte Sinaí y el Santo Sepulcro de Jerusalén. Son en todos los casos imágenes convencionales de edificios basilicales, alejados de su realidad arquitectónica; esto se pone especialmente de relieve en el caso de Jerusalén, donde la Rotonda del Santo Sepulcro, un edificio de planta central, se representa de forma longitudinal ${ }^{24}$. Como se aprecia en la carta de Mecia de Viladestes (1413), pese al convencionalismo de la ilustración, el Santo Sepulcro de Jerusalén se diferencia de todos los restantes santuarios al incorporar una estructura en su lateral mayor. El origen de este detalle se remonta a Angelino Dulcert, quien, tanto en su carta atribuida de la primera mitad del siglo XIV como en la que firma en 1339, adosó al edificio una estructura a modo de arqueta con tapa en talud y coronada con una cruz, que podría identificarse con el edículo que contuvo el cuerpo de Cristo hasta su Resurrección. Dicha estructura tendió a enfatizarse mediante el color, como en la carta de Guillem Soler (ca. 1380), o por estar acogida bajo una

${ }^{22}$ M. HERRERA CASAIS, "Granada en los atlas náuticos de al-Šarafī, e identificación de un modelo mallorquín para al-Mursī”, Al-Qanțara, 30:1 (2009), p. 224.

23 R. CARANDE y J. DE M. CARRIAZO (dirs.), El tumbo de los Reyes Católicos del Concejo de Sevilla, t. 5, Sevilla, 1971, p. 98. En relación con este documento epistolar, véase J. PÉREZ, Isabel y Fernando: los Reyes Católicos, Madrid, 2001, p. 154 (1ª ed. 1988); y L. SUÁREZ FERNÁNDEZ, Los Reyes Católicos: el tiempo de la guerra de Granada, Madrid, 1989, pp. 20-21.

24 Dada la falta de realismo de esta representación, rechazo la afirmación de G. Llompart i Moragues de que Cresques Abraham conoció este edificio en un viaje a Tierra Santa, en G. LLOMPART I MORAGUES, "Aspectes iconogràfics", CRESQUES ABRAHAM, L'atlas catala de Cresques Abraham, Barcelona, 1975, p. 49. 
moldura decorativa lobulada, de enorme protagonismo en la carta de Mecia de Viladestes $(1423)^{25}$.

\section{La geografía veterotestamentaria según un judeoconverso}

Las cartas náuticas incorporan además muchos motivos procedentes del Antiguo Testamento, como son el arca de Noé posada sobre el monte Ararat tras el Diluvio universal (Génesis, VIII, 4); el paso del Mar Rojo por el pueblo de Israel en su Éxodo hacia la Tierra Prometida (Éxodo, XIV, 21-22); el Monte Sinaí al que Moisés subió para recibir las Tablas de la Ley (Éxodo, XXIV, 12-18); o la ciudad de Nínive destruida por la ira de Dios debido a sus pecados (Nahum II, 13-III, 19). Aunque en principio la procedencia veterotestamentaria de estos temas podría hacerlos representativos tanto del cristianismo como del judaísmo, es interesante señalar que en algunas cartas mallorquinas, concretamente en aquellas realizadas por cartógrafos judíos o judeoconversos, se concede una especial atención a los mismos. Tal es el caso de Cresques Abraham y su Atlas Catalán (1375) ${ }^{26}$, y de los mapas de Mecia de Viladestes, quien fue obligado a convertirse al cristianismo a raíz del progrom antijudío de 1391 . Su carta de 1413 presenta ciertos detalles de los que prescinden la mayoría de las cartas restantes -como la importancia que concede al Dios del Antiguo Testamento y a su profeta Moisés-. Dichos detalles indican un profundo conocimiento de su autor del judaísmo o bien que, pese a su conversión, aún comulgaba con la religión hebrea.

El Mar Rojo es fácilmente discernible por estar policromado del color de su nombre (fig. 1). La península del Sinaí aparece representada mediante dos lóbulos, de los cuales, el más occidental está atravesado por una banda a modo de calle para evocar el paso del pueblo de Israel. La información que las cartas náuticas ofrecen sobre ese mar alude al acontecimiento bíblico: inicialmente solo mencionaban el Mar Rojo como el lugar atravesado por los israelitas, por ejemplo, en la carta de Angelino Dalorto (1330): Hic transivic (sic) filliorum Irsaell (sic) ${ }^{27}$; y posteriormente, desde el Atlas Catalán (1375) de Cresques Abraham, se añadió que el pueblo de Israel salía de Egipto: Per aquest freu pasaren los fills d'Israel con ixiren de Gipte ${ }^{28}$. En el tratamiento de este tema, la carta de 1413 de Mecia de Viladestes se desmarca de todas

25 Biblioteca Medicea Laurenziana, Florencia (Ashb. nº. 1802). Para una reproducción de este mapa, véase R.J. PUJADES I BATALLER, op. cit., 2007, fig. C34, pp. 238-239.

26 Para la identificación de Cresques Abraham como un autor judío, véase J. BENSAÚDE, L'astronomie nautique au Portugal à l'époque des grandes découvertes, Berna, 1912, pp. 94-95; C. DE LA RONCIÈRE, La découverte de l'Afrique au Moyen Âge. Cartographes et explorateurs, vol. 1, El Cairo, 1925, p. 125; J. RIERA I SANS, "Cresques Abraham, jueu de Mallorca, mestre de mapamundis i de brúxoles", CRESQUES ABRAHAM, op. cit., 1975, p. 15; y G. LLOMPART I MORAGUES, La pintura medieval mallorquina, su entorno cultural y su iconografía, Palma de Mallorca, 1977, v. 1, p. 177.

27 R.J. PUJADES I BATALLER, "La història de l'Atles català i l'eniga de l'autor", CRESQUES ABRAHAM, op. cit., 2005, p. 38.

28 Ibid. 
las anteriores al especificar que los hijos de Israel salieron de Egipto "por mano de Moisés", al que el cartógrafo llama "profeta de Dios": Per aquest loch passaren lo fils d'Israel con isqueren d'Egipta per ma de Moyses profeta de Deu ${ }^{29}$.

Por lo que respecta al Monte Sinaí, las primeras cartas que lo identifican como el lugar en el que Moisés recibió las Tablas de la Ley cometen el error de aludir a la aparición de Jesús -y no de Dios-. Así ocurre en la carta de Angelino Dalorto $(1330)^{30}$ y en la de los hermanos Pizzigani $(1367)^{31}$. La equivocación se corrige en el Atlas Catalán ${ }^{32}$, lo que perdura de forma prácticamente idéntica en las cartas derivadas de su taller, como las anónimas de París ${ }^{33}$ y Nápoles ${ }^{34}$. Mecia de Viladestes incrementa el contenido de esta leyenda en su carta de 1413 y hace referencia al Dios del Antiguo Testamento como "nuestro Señor", califica de "santa" a la ley divina y reitera la idea de que fue recibida "por mano del profeta Moisés": Aquest mont es apelat Sinay en lo dit mont dona nostra Senyor Déu la ley santa al poble d'Irael per ma de Moisés prafeta. Además de la importancia textual que Mecia de Viladestes concede a este tema bíblico, es interesante poner de relieve que, mientras que la mayoría de las cartas se limitan a ilustrar solo el monasterio de Santa Catalina allí emplazado, este cartógrafo, en su carta de $1413^{35}$, dispone en la cima del monte otro santuario con el que quizá trataba de conmemorar el lugar en el que Moisés recibió las Tablas de la $\operatorname{Ley}^{36}$ (fig. 1). Sin duda alguna, este tema cobró gran relevancia en el seno de la cultura judía de estos cartógrafos, y especialmente de Mecia de Viladestes, ya que aparece reiterado en el documento más importante que conservamos de este cartógrafo, aquel en el que con su nombre de judío, Samuel Corchos, se presenta como sirviente y aprendiz de Jafuda Cresques ${ }^{37}$.

29 Este añadido es reiterado de forma muy semejante por Joan de Viladestes (1428): "Per aquest pas passaren los fills de Israel com hisqueren de Egipte per ma de la propheta Moyses".

30 Desertum Sinay, in quo Jhesus aparuit Moysie, en R.J. PUJADES I BATALLER, op. cit., 2005, p. 40.

31 Biblioteca Palatina, Parma (Ms. 1612). Para una reproducción de este mapa, véase G. CAVALLO, op. cit., 1992, vol. 1, pp. 432-433. La leyenda reza: Mons Sinay quo (in quo) dominus jesus a de (aut deus) moyss instrudebat et ey (ei) legem cunferebat (conferebat) propter populum, M. LONGHENA, "La carta dei Pizigano del 1367 (posseduta dalla Biblioteca Palatina di Parma)", Archivio Storico per le Province Parmensi, 5 (1953), p. 106.

32 R.J. PUJADES I BATALLER, op. cit., 2005, p. 43. El texto de este mapa dice: Mont de Sinay en lo qual Déu donà la Ley a Moyssès. Hic est corpus Catarina virginis, ibid., p. 40.

33 BnF, París (Rés. Ge. AA 751). Para una reproducción de esta carta, véase R.J. PUJADES I BATALLER, op. cit., 2007, fig. C22, pp. 178-179. El texto de este mapa dice: Hic est corpus Catarina virginis. Mont de Sinay, en lo qual Déus donà [la lley a] Moissès, R.J. PUJADES I BATALLER, op. cit., 2005 , p. 40.

34 Biblioteca Nazionale Vittorio Emanuele III, Nápoles (Sala Direzione, Ms. XII D 102). Para una reproducción de esta carta, véase G. CAVALLO, op. cit., 1992, vol. 1, fig. II.15, pp. 326-327; y R.J. PUJADES I BATALLER, op. cit., 2007, fig. C19, pp. 164-165. El texto de este mapa dice: Mont de Sinay, en lo qual Déus donà la lley a Moissès, R.J. PUJADES I BATALLER, op. cit., 2005, p. 40.

35 Esta construcción está también representada en la carta de Joan de Viladestes (1428), y previamente, de forma esquemática, en la de Guillem Soler (ca. 1380).

36 La mención más antigua a una construcción en la cima del monte Sinaí aparece en el Itinerario de la monja Egeria del siglo IV.

37 Arxiu del Regne de Mallorca, Palma de Mallorca (Prot. Not. Nicolau de Cases, N-2421 (1387-1391), fols. 123r-123v); recogido en G. LLOMPART I MORAGUES y J. RIERA I SANS, “Jafuda Cresques i 


\section{La interpretación occidental de la peregrinación musulmana a La Meca}

Debemos volver a las alusiones que las cartas náuticas conceden al islam para ocuparnos de uno de los motivos iconográficos más interesantes: la imagen de un peregrino musulmán en oración ante la representación de La Meca ${ }^{38}$ (fig. 1). El personaje de la carta de Mecia de Viladestes (1413) es de color, y por ello sabemos que posiblemente había llegado a la península Arábiga desde el Occidente africano, ya que las cartas náuticas identifican esta región como la "tierra de negros"39. Además, muchos de estos mapas -aunque no los de Mecia de Viladestes- incorporan junto al Atlas africano una leyenda en la que afirman que esa cordillera es la vía de peregrinación a La Meca ${ }^{40}$.

La representación de un peregrino musulmán en oración ante la ciudad sagrada del Islam se remonta a la carta de Angelino Dalorto (1330), y es reiterada en otros mapas con posterioridad, tales como la carta de los hermanos Pizzigani (1367) o el Atlas Catalán (1375) de Cresques Abraham. El peregrino de estos tres últimos mapas aparece de rodillas y con las manos juntas, en una postura nada relacionada con el rezo musulmán, sino con la oración cristiana ${ }^{41}$. El desconocimiento con el que se entiende la șalät, es decir, la oración islámica, no es exclusivo de estos mapas, sino que aparece también reflejado dentro de la literatura, por ejemplo, en la Chanson de Roland (finales del siglo XI), donde se afirma que "los paganos inclinan sus cabezas y sus mentones y bajan hacia delante sus brillantes yelmos" ${ }^{\text {"42 }}$. Por su parte, y con anterioridad, Álvaro de Córdoba (siglo IX) desestimaba la forma islámica de orar al describirla de la siguiente forma en su Indiculus luminosus:

"La oración de los desobedientes es hecha pecaminosamente y con continua encorvadura de la espalda y los repetidos golpes de cabeza, que ostentando su jactancia clavan frecuentísimamente en tierra, no les proporciona la salvación, sino el suplicio eterno" ${ }^{43}$.

Samuel Corcós. Més documents sobre el jueus pintors de cartes de navegar (Mallorca, s. XIV)", Boletín de la Sociedad Arqueológica Luliana, 40 (1984), pp. 349-350.

${ }_{38}$ Para la representación del peregrino musulmán y el santuario de La Meca en los mapas, véase $\mathrm{S}$. SÁENZ-LÓPEZ PÉREZ, "La peregrinación a La Meca en la Edad Media a través de la cartografía occidental", Revista de poética medieval, 19 (2007), pp. 177-218.

39 Por ejemplo, el inicio del texto referente al Sultán Musa de la carta de Mecia de Viladestes (1413) reza: REX MUSA MELI. Aquest senyor dels negres es apelat Musa Meli....

40 Véase ibid., pp. 179-182.

${ }^{41}$ Para este gesto, véase J.C. SCHMITT, La raison des gestes dans l'occident medieval, París, 1990, pp. 295-301. Debido a la falta de precisión en la representación de esta figura no comparto la idea de Gabriel Llompart i Moragues de que la del Atlas Catalán podría derivar de un musulmán en oración que el cartógrafo viera en la isla, G. LLOMPART I MORAGUES, Les il-lustracions religioses de l'atlas mallorquí del jueu Cresques Abraham..., Palma de Mallorca, 1989, p. 9. El peregrino de la carta de Mecia de Viladestes (1413) levanta los brazos en actitud orante, más próxima al rezo islámico.

${ }^{42}$ Cantar de Roldán (CCXXXVI), I. DE RIQUER (trad.), Madrid, 1999, p. 201.

${ }^{43}$ F. DELGADO LEÓN, Álvaro de Córdoba y la polémica contra el islam. El "Indiculus luminosus", Córdoba, 1996, p. 165. 
Además, ninguno de los peregrinos musulmanes de las cartas náuticas viste tal como prescribe el haŷy o la peregrinación a La Meca, pues presentan la cabeza cubierta, y no están ataviados con el iḥrām, que deja el hombro al descubierto $^{44}$.

Como apreciamos en la carta de Mecia de Viladestes (1413), La Meca sigue el modelo convencional de ciudad islámica -con torres rematadas en almenas y cúpula- aunque adquiere grandes dimensiones, y presenta dos cercos de muralla yuxtapuestos; quizá el más frontal y más visible se correspondería con la Mezquita Sagrada hacia la que se dirige el peregrino. Sobre La Meca flota un objeto dorado, rematado en formas lobuladas, que, gracias a su explicación textual, podemos interpretar como el arca de Mahoma que se sostiene en el aire por virtud de la calamita o imán: Meca on és l'archa de Mafumet, qui-s sosté en l'aer sots molta de caramida, la qual [é]s onrada entró al jorn de uiy per tots los sarayns.

El origen de la representación de este último detalle dentro de la cartografía náutica se remonta a la carta de Angelino Dalorto (1330), en la que encontramos una mancha negra entre dos altas torres. Según explica el texto, se trata del Arca Macometo que permanece en el aire ${ }^{45}$, y el color oscuro podría deberse a la representación de la piedra imán. El estudio en profundidad de este mismo tema en otros mapas evidencia que ese "arca de Mahoma" no es otra cosa que el receptáculo en el que se guardan sus restos. A partir de las cartas de Angelino Dulcert (la atribuida de la primera mitad del siglo XIV, y 1339) este objeto adquiere forma de arqueta, es decir, de caja rectangular con tapa de laterales en talud, muy semejante a la estructura que, nuevamente desde Angelino Dulcert, encontrábamos adosada al Santo Sepulcro. Por ello, podemos afirmar que la forma de arqueta de estos mapas se asocia a la idea de sarcófago o relicario. El arca de Mahoma de la carta de Guillem Soler (ca. 1380) incorpora en su base pequeñas patitas, que, sin embargo, no la soportan porque flota en el aire (fig. 2). Su texto es especialmente explícito a la hora de desvelar su significado, ya que afirma que la sepultura de Mahoma está en La Meca (y no en Medina, donde realmente se halla): Mecha en esta ciutat és la sepultura de $M$ [afume]t, profeta fals dels ser[ayns los] quals vénan ací en $p$ [elegri] natge de totes lus [parts], e aquí éls se fan abacinar [la vista per r]auerència de $M a f u[\text { met }]^{46}$.

${ }^{44}$ Véase Encyclopédie de l'Islam, t. III, Leiden, 1975, s.v. "ihrām”, pp. 1078-1079; y W.C. YOUNG, "The Kaba, Gender, and Rites of Pilgrimage", International Journal of Middle East Studies, 25:2 (1993), pp. 285-300, esp. 290-291.

${ }_{45}$ Turis Mecha: in quo permanet archa legis Machometo in aerem, R.J. PUJADES I BATALLER, op. cit., 2005, p. 40.

46 Ibid., p. 41. Guillem Soler reitera esta leyenda en su carta de 1385: Mecha en esta ciutat és la sepultura de $M$ [afume]t, profeta fals dels sera[yns, les q]uals uenan ací en $p$ [elegr]inatge de totes lus [parts], e aqui els se fan abacinar [la vista en r]auerencia de Mafu[met]. 

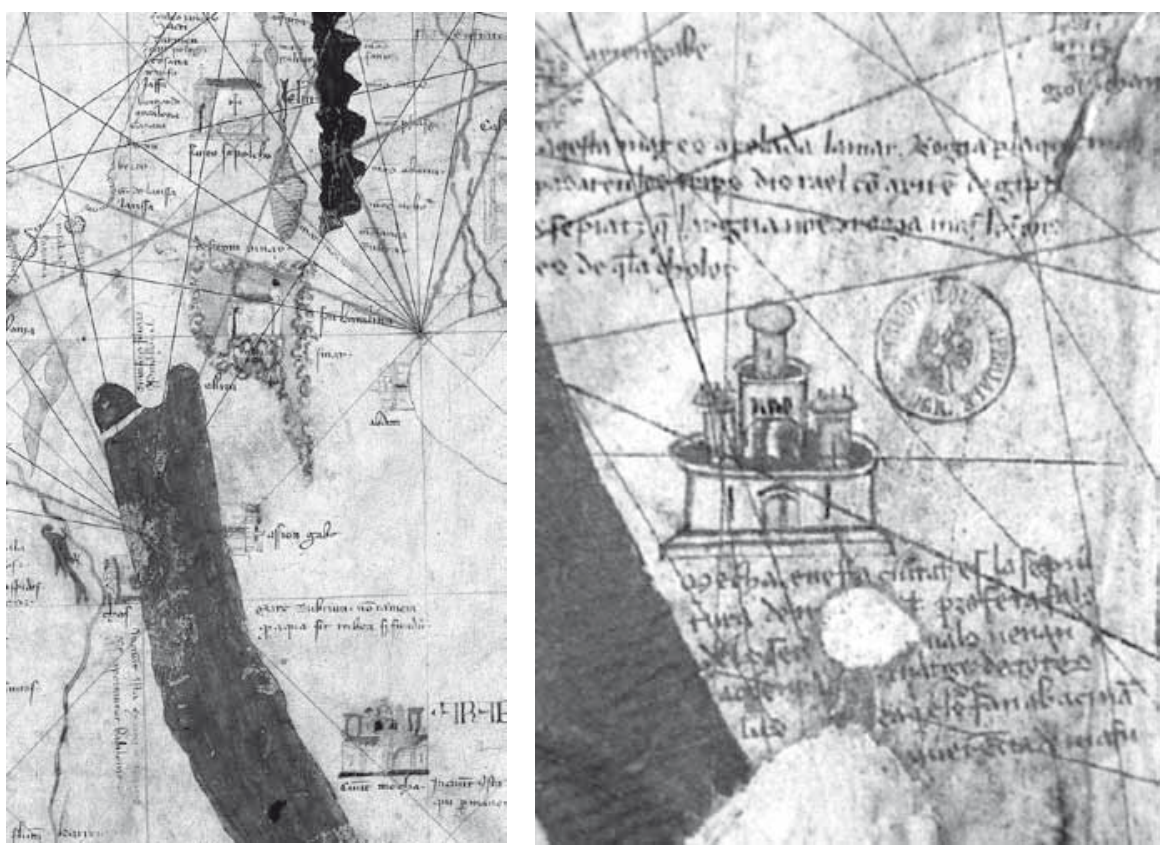

Fig. 2. Carta de Guillem Soler (ca. 1380), detalle de La Meca y el arca de Mahoma. (BnF, París, Rés. Ge B 1131).

La forma de arqueta del arca de Mahoma de estos mapas recuerda a sarcófagos o recipientes funerarios que fueron utilizados en la Edad Media occidental para contener reliquias; por ejemplo, la arqueta islámica de Leyre (395 H./1005 d.C. $)^{47}$, reutilizada por los cristianos para albergar las reliquias de las santas Nunilona y Alodia en el monasterio de San Salvador de Leyre (Navarra) (fig. 3). Quizá la razón de la semejanza del arca de Mahoma de estos mapas con las arquetas de reliquias cristianas se deba a que, para representar el sarcófago de Mahoma adorado por los musulmanes, los cartógrafos occidentales recurrieron a objetos que les eran familiares, y que cumplían con una finalidad semejante.

Es sin duda llamativo que la Edad Media occidental desconociera aspectos tan importantes del mundo musulmán como el hạyy, uno de los cinco "pilares del islam". Su concepción errónea no es exclusiva de estos cartógrafos, sino que formó parte de las tergiversaciones a las que se sometieron en Occidente las creen-

47 Museo de Navarra, Pamplona. Para la arqueta de Leyre, véase Al-Andalus. Las Artes Islámicas en España, Nueva York, 1992, pp. 182-201; y N. SILVA SANTA-CRUZ, "Marfiles”, A.E. MOMPLET MÍGUEZ, El arte hispanomusulmán, Madrid, 2004, pp. 266-267. 


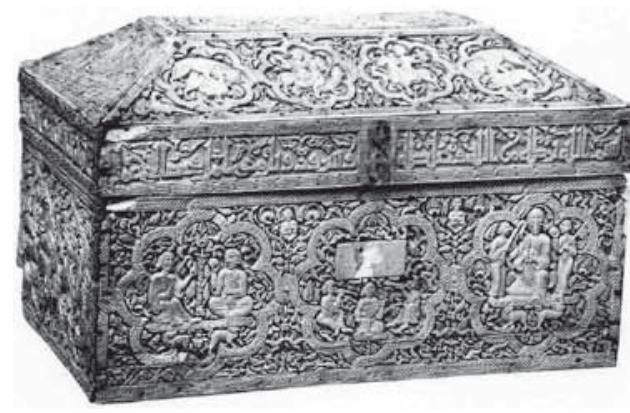

Fig. 3. Arqueta de Leyre, 395 H./1005 d.C. (Museo de Navarra, Pamplona). cias relacionadas con Mahoma ${ }^{48}$. Según Samuel C. Chew $^{49}$, el origen de esta idea se remonta al siglo XI, y está recogida ya en el poema latino de la Historia de Mahumete de Hildeberti, Arzobispo de Tours $(1055-1133)^{50}$. Dicha creencia experimentó una muy larga continuidad, y fue difundida, entre otros, por los viajeros que fueron, o dijeron haber ido, a tierras foráneas. Así por ejemplo, Odorico da Pordenone (ca. 1265-1331) decía en su Itinerarium que: La Meca... [es] donde yace Mahoma. Los sarracenos suelen ir a esta ciudad de La Meca de la misma manera que los cristianos van al Sepulcro ${ }^{51}$.

Es sin duda difícil determinar el origen de este error. Quizá pudo derivar de la influencia de otras creencias de sarcófagos suspendidos en el aire, tales como el del apóstol Santo Tomás ${ }^{52}$, o, como plantea Samuel C. Chew, de una mala interpretación de leyendas propiamente islámicas ${ }^{53}$ : en el Viaje Nocturno de Mahoma, la piedra sobre la que dormía en La Meca intentó seguirle en su ascenso hacia Jerusalén, pero Mahoma le prohibió continuar subiendo, quedando de este modo la roca suspendida en el aire; en este mismo viaje, la piedra que posteriormente sería venerada en la Cúpula de la Roca intentó igualmente seguir a Mahoma en su ascenso al cielo, siendo frenada por el ángel Gabriel que dejó grabada su huella en ella ${ }^{54}$.

48 Para la leyenda occidental de Mahoma, véase A. D’ANCONA, "La leggenda di Maometto in Occidente", Giornale storico della letteratura italiana, 13 (1889), pp. 199-281; V. CHAUVIN, Bibliographie des ouvrages arabes ou relatifs aux arabes, publiés dans l'Europe chrétienne de 1810 à 1885, vol. XI, Lieja, 1909, pp. 212-234; D.C. MUNRO, "The Western Attitude toward Islam during the Period of the Crusades", Speculum, 6 (1931), pp. 329-343; A. MANCINI, "Per lo studio della leggenda di Maometto in Occidente", Rendiconti della R. Accademia Nazionale dei Lincei, 10 (1934), pp. 325-349; M.C. DÍAZ Y DÍAZ, "Los textos antimahometanos más antiguos en códices españoles", Archives d'Histoire Doctrinale et Littéraire du Moyen Âge, 37 (1970), pp. 149-164; B. PENA, "La imagen de Mahoma en la España medieval: una aproximación a los autores cristianos", Tesis Doctoral, Los Ángeles, University of Southern California, 1981; E.W. SAID, Orientalism, Londres, 1995, pp. 55-73; e I. MONTEIRA ARIAS, "La escultura románica hispana y la lucha contra el Islam (mediados del siglo XI a mediados del siglo XIII)", vol. 1, Tesis Doctoral, Universidad Carlos III de Madrid, Madrid, 2010, pp. 86-141.

49 S.C. CHEW, The Crescent and the Rose: Islam and England during the Renaissance, Nueva York, 1974 , p. 414.

50 Véase J.P. MIGNE, P.L., CLXXI, cols. 1364-1365; y E. DU MERIL, Poésies populaires latines du moyen âge, París, 1847 , p. 414, nota 3.

51 ODORICO DA PORDENONE, Relación de Viaje, Buenos Aires, 1987, p. 55.

52 Véase S.C. CHEW, op. cit., 1974, pp. 414-415, para una recopilación de ejemplos en los que se alude a fenómenos de suspensión o tumbas con propiedades físicas semejantes. Para el sarcófago de Santo Tomás, véase F. ZARNCKE, "Der Bericht des Elysaeus”, Der Priester Johannes, Leipzig, 1879, pp. 122-127, esp. p. 123.

53 S.C. CHEW, op. cit., 1974, pp. 415-416.

54 En relación con esta leyenda, véase H. ADOLF, "Christendom and Islam in the Middle Ages: New Light on 'Grail Stone' and 'Hidden Host'”, Speculum, 32:1 (1957), pp. 103-115, esp. 110-112. 
Igualmente, podríamos mencionar que según la creencia de algunos autores, como el arzobispo de Toledo Rodrigo Jiménez de Rada (ca. 1170-1247) ${ }^{55}$, la Piedra Negra de la Kacba era una piedra magnética que soportaba el sarcófago de Mahoma.

\section{Los dioses indios de "nueve cabezas y nueve manos"}

Otra de las imágenes religiosas de la carta de Mecia de Viladestes (1413) de gran interés aparece localizada en el noreste de Europa, aunque la escena hace referencia a un ritual religioso indio. Frente a un ídolo dorado dispuesto sobre un pedestal figura un personaje con atavío orientalizante -como se puede apreciar en el tocado puntiagudo-, que está arrodillado y con las manos juntas, repitiéndose así,

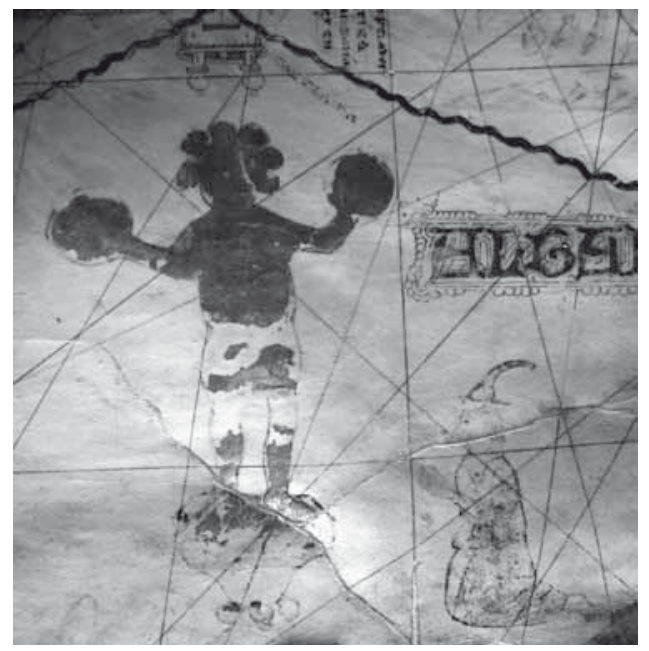

Fig. 4. Carta de Mecia de Viladestes (1413), detalle de divinidad de la India adorada por un personaje en oración (BnF, París, Rés. Ge. AA 566). nuevamente, el gesto cristiano de oración (fig. 4). La escultura presenta forma antropomorfa, aunque tiene las manos ensanchadas, como si sostuviera platos, y su cabeza está rodeada de formas redondeadas a modo de diadema. La imagen se representó con anterioridad en un mapa circular (ca. 1375-1380) ${ }^{56}$, del que se conserva solo un fragmento, y posteriormente en el Mappamundi Catalán Estense (ca. 1450) ${ }^{57}$.

En estos dos mapas, sin embargo, figuran dos personajes flanqueando al ídolo, que no es de oro, sino de plata, actualmente oscurecida por la oxidación. Asimismo, la carta de Juan de la Cosa $(1500)^{58}$ reiteró este motivo por influencia de la cartografía mallorquina ${ }^{59}$. Junto

55 Véase Rodrigo JIMÉNEZ DE RADA, “De Instrvctione et prima ostensione Machometi”, Historia Arabvm, II, Sevilla, 1993, pp. 5-6.

56 Topkapi Sarayi, Estambul (H. 1828). Para una reproducción de este mapa, véase M. DESTOMBES, "Fragments of Two Medieval World Maps at the Topkapu Saray Library", Imago Mundi. The International Journal for the History of Cartography, 12 (1955), pp. 150-152; con los pies de fotos invertidos y corregidos en 13 (1956), p. 193.

57 Biblioteca Estense Universitaria, Módena (C.G.A.1). Para una reproducción de este mapa, véase E. MILANO y A. BATINI, Mapamundi Catalán Estense, Barcelona, 1996; y Antichi planisferi e portolani: Modena, Biblioteca estense univesitaria [CD-ROM], Módena-Milán, 2004.

58 Museo Naval, Madrid (MN 257). Para una reproducción facsimilar de este mapa, véase JUAN DE LA COSA, Carta de Juan de la Cosa: año de 1500, Madrid, 1992.

59 Para la influencia de la cartografía mallorquina en la carta de Juan de la Cosa, véase S. SÁENZLÓPEZ PÉREZ, "La Carta de Juan de la Cosa (1500), colofón de la cartografía medieval”, A. ROS TOGORES (coord.), Piezas del Mes, Museo Naval de Madrid, 2003/2005, Madrid, 2006, pp. 10-31, esp. pp. 17-27. 
a la imagen figura la leyenda Ydolo de ydolatras, aunque el mapa prescinde de la representación de estos últimos. En esta carta podemos distinguir que las formas redondeadas de las manos y cabeza del ídolo presentan rostros, de lo que se deduce que la figura estaba dotada de una multiplicidad de cabezas. El texto explicativo de la escena está prácticamente perdido en la carta de Mecia de Viladestes, pero podemos recuperar su contenido gracias al Mappamundi Catalán Estense, en el que la leyenda reza: Ciutat de Castrema. En sta prouiincia a jens idolatrechs, los quals adoran vna idolla da matall ab nou caps e nou mans e fan na lur dues... ${ }^{60}$.

Esta descripción textual del "ídolo de metal con nueve cabezas y nueve manos" alude sin duda alguna a una deidad india. Europa comenzó a entrar en contacto con el arte indio a mediados del siglo XIII, gracias a las narraciones de viajeros como Marco Polo que habían llegado hasta él. Sin embargo, ese conocimiento que del arte indio le fue transmitido a Occidente estaba lleno de errores y prejuicios, fruto del trasfondo cristiano de estos viajeros y de la enorme distancia cultural que existía entre ambos contextos culturales ${ }^{61}$. Como resultado, las estatuas de los dioses indios tendieron a representarse con formas estereotipadas o monstruosas. Así lo pone de relieve Partha Mitter ${ }^{62}$ en el análisis de la que este investigador considera es una de las más tempranas ilustraciones occidentales de un dios indio: la imagen de la celebración religiosa de las devadāsīs de Maabar (India) en honor de su diosa, presente en el manuscrito de Il Milione de Marco Polo del Duque de Berry (ca. 1410-1412) ${ }^{63}$. Según el mercader veneciano:

"Hay muchos ídolos en sus monasterios, machos y hembras, y muchas doncellas les están dedicadas; su padre y su madre las consagran a su ídolo preferido.... Mas una vez ofrendadas, cada vez que las monjas del monasterio de los ídolos reclaman a estas doncellas para que festejen en el templo a su dios, vienen ellas en seguida y cantan y tocan muchos instrumentos y danzan con gran fiesta y regocijo.... Varias veces a la semana o al mes llevan comida al ídolo al que están dedicadas"64.

Posiblemente, influenciado por el lenguaje empleado por Marco Polo, el Maestro de Boucicaut, quien trabajó en este manuscrito, ilustró a las mujeres indias

60 "Ciudad de Castrema. En esta provincia hay gente idólatra que adoran un ídolo de metal con nueve cabezas y nueve manos y le consideran su dios...", A. BATINI, “Transcripción”, E. MILANO y A. BATINI, op. cit., 2004, p. 153.

${ }_{61}$ Debemos señalar no obstante las semejanzas existentes entre el cristianismo y el budismo que ya los primeros viajeros occidentales a Asia pudieron apreciar, como se desprende de M. BACCI, "Cult-Images and Religious Ethnology: The European Exploration of Medieval Asia and the Discovery of New Iconic Religions", Viator. Medieval and Renaissance Studies, 36 (2005), pp. 337-372, esp. 352-367. Gracias a Francisco de Asis García García por darme a conocer esta publicación.

62 P. MITTER, Much Maligned Monsters: History of European Reactions to Indian Art, Oxford, 1977, pp. 3-6.

${ }^{63}$ BnF, París (Ms. français 2810, fol. 80r). Esta ilustración está reproducida en www.mandragore.bnf.fr (última consulta 11/01/2011); y P. MITTER, op. cit., 1977, p. 4.

${ }^{64}$ MARCO POLO, Viajes, Madrid, 1998, p. 420; he modificado esta traducción (la parte en cursiva), para ajustarme al texto original, tal como explica P. MITTER, op. cit., 1977, nota 3, p. 287. 
como monjas y a su diosa muy parecida a ellas, salvo por el color oscuro de la piel, que, como afirma Michael Camille, le otorga una connotación negativa ${ }^{65}$.

Las representaciones de los ídolos indios en las cartas náuticas son sin duda interesantes por ser anteriores a este manuscrito de Marco Polo. Además, los cartógrafos han sido algo más fieles a la noción que de los dioses indios se tenía en Occidente, al intentar plasmar la multiplicidad de brazos y cabezas que tanto llamó la atención ${ }^{66}$. Sin embargo, en ningún caso, las imágenes de los mapas se acercan a la iconografía budista o hindú, presente, por ejemplo, en Shiva con cuatro brazos y tres cabezas (Tamil Nadu, India, siglo X) ${ }^{67}$ (fig. 5). Los cartógrafos optaron de nuevo por recursos gráficos que les eran familiares, y que encontramos dentro del arte occidental, por ejemplo, en las ilustraciones de la estatua de muchos metales con la que Nabucodonosor soñó (Daniel, II, 31-35) ${ }^{68}$, o aquella de oro que este soberano babilónico mandó levantar, y ante la que todos los pueblos se postraron (Daniel, III, 1-7). Representaciones de este último tema podríamos encontrar, por ejemplo, en algunos manuscritos del Comentario al Apocalipsis de Beato de Liébana, tales como el códice de Fernando I y Sancha $(1047)^{69}$, en el que la gran estatua de me-

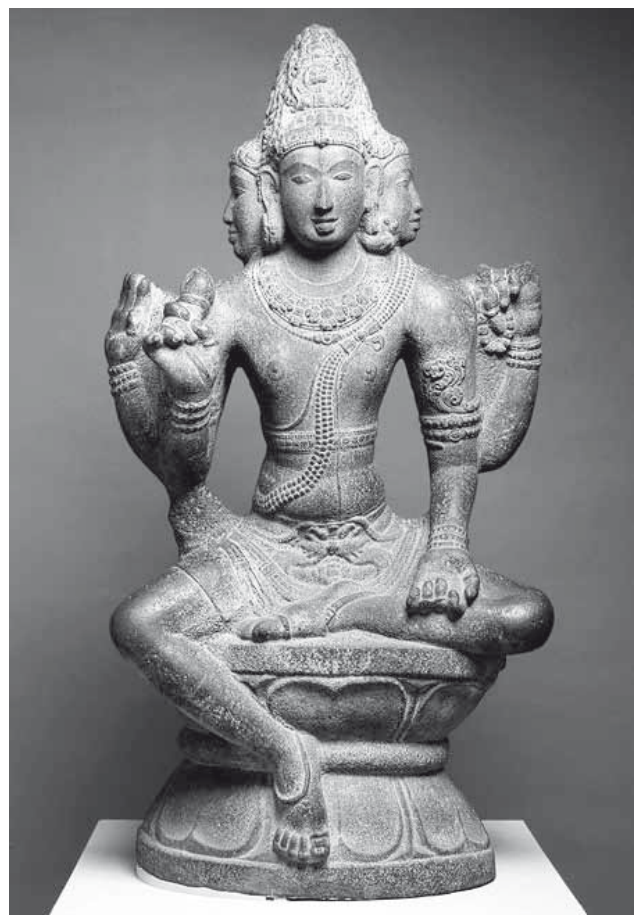

Fig. 5. Shiva con cuatro brazos y tres cabezas (Tamil Nadu, India, siglo X) (Metropolitan Museum of Art, Nueva York, Egleston Fund, 1927, 27.79). p. 160 .

65 M. CAMILLE, The Gothic Idol: Ideology and Image-Making in Medieval Art, Cambridge, 1989,

66 Véase P. MITTER, “Indian Art in Travellers' Tales”, op. cit., 1977, pp. 1-104.

67 The Metropolitan Museum of Art, Nueva York (Egleston Fund, 1927, 27.79). Para la multiplicidad de miembros y cabezas de la escultura india, véase A. K. COOMARASWAMY, "Indian Images with Many Arms", The Burlington Magazine for Connoisseurs, 22, 118 (1913), pp. 189-191 y 194-196; y D.M. SRINIVASAN, Many Heads, Arms, and Eyes: Origin, Meaning, and Form of Multiplicity in Indian Art, Leiden, 1997, quien explica que esa multiplicidad de brazos y cabezas alude a la capacidad creadora cósmica. Y para la influencia de la imaginería india en la occidental, J. BALTRUŠAITIS, La Edad Media fantástica, Madrid, 1983, pp. 197-200.

${ }_{68}$ Para representaciones de este pasaje bíblico en el arte medieval, véase M. CAMILLE, op. cit., 1989, pp. 281-288.

69 Biblioteca Nacional de España, Madrid (Ms. Vitr. 14-2, fol. 274v). Para una reproducción de este manuscrito, véase BEATO DE LIÉBANA, Commentarium in Apocalypsim. El Beato de Liébana, códice de Fernando I y doña Sancha, 2 vols., Madrid-Barcelona, 1994. 
tal está siendo adorada por una multitud de personajes que se reclinan a ambos lados.

\section{A modo de conclusión}

Como hemos visto en la carta de Mecia de Viladestes (1413) y en otras relacionadas con ella, los cartógrafos medievales concedieron gran importancia a la representación de la geografía religiosa, haciendo así alarde en sus mapas de las diferentes creencias que existían en el mundo medieval. Aunque estas representaciones no están faltas de inexactitudes y errores, fruto de la imposición de prejuicios cristianos y del limitado conocimiento que Occidente tenía especialmente de aquellos cultos que le resultaban más ajenos -como el islam o las religiones indias-, ponen de relieve el interés del hombre de la Edad Media occidental por conocer otras creencias.

Gracias a la información documental sabemos que en 1381 el infante don Juan de Aragón mandó como presente al nuevo monarca francés, Carlos VI, el Atlas Catalán (1375). Y a su mensajero, Mossén Guillem de Courcy, le encargó que buscara a su autor, Cresques Abraham, para que le proporcionara toda la información necesaria de esta obra y que a su vez se la comunicara al rey francés ${ }^{70}$. Podemos imaginar que entre esa información requerida habría cabida para explicaciones sobre la pluralidad religiosa del mundo. Por su parte, desconocemos a quién iba destinada la carta de Mecia de Viladestes (1413), pero quizá intervinieron en su encargo manos religiosas, pues siglos más tarde, Joaquín Lorenzo de Villanueva la localizó en la Cartuja de Valldecrist (Castellón) $)^{71}$. Gracias a mapas como estos sus destinatarios, cristianos de Occidente, pudieron contemplar la imagen de un mundo en el que el cristianismo coexistía, e incluso a veces convivía, con otras religiones.

70 Arxiu de la Corona d'Aragó, Barcelona (Reg. 1665, fol. 26); recogido en A. RUBIÓ I LLUCH, Documents per l'historia de la cultura catalana mig-eval, vol. 1, Barcelona, 1908, p. 295. Para la identificación del Atlas Catalán con el mapa mencionado en este documento, véase J. RIERA I SANS, op. cit., 1975, p. 14.

71 J.L. VILLANUEVA, Viage literario a las iglesias de España, t. IV, Madrid, 1806, pp. 24-31. 